\title{
Lymphocyte Antigens in Systemic Lupus Erythematosus
}

\author{
STUDIES WITH HETEROLOGOUS ANTISERA
}

\author{
Ralph C. Williams, Jr., G. R. V. Hughes, M. L. Snaith, H. F. Parry, E. Diao, \\ and M. F. Greaves, Membrane Immunology Laboratory, \\ Imperial Cancer Research Fund, Lincolns Inn Fields, Division of Rheumatology, \\ Department of Medicine, Royal Postgraduate Medical School, \\ Hammersmith Hospital, and Department of Rheumatology and Rehabilitation, \\ University College Hospital, London, England; Department of Medicine, \\ University of New Mexico School of Medicine, Albuquerque, New Mexico 87111
}

\begin{abstract}
A B S T R A C T Rabbit antisera were produced against pooled living lymphocytes from 25 patients with active systemic lupus erythematosus (SLE). Lymphocytes collected at plasmapheresis or venipuncture were frozen in liquid nitrogen and later coated with rabbit antibody to normal human tonsils and normal thymocytes immediately before intravenous immunization of rabbits. Antisera were subsequently extensively absorbed with normal human tonsillar cells, thymocytes, peripheral blood lymphocytes, erythrocytes, and leukocytes from patients with myelogeneous and lymphatic leukemia until residual base-line immunofluorescent staining of normal human lymphocytes using $\mathrm{F}(\mathrm{ab})_{2}{ }^{\prime}$ of whole antisera averaged $<5 \%$. Absorbed pepsin-digested antisera detected membrane antigens which were markedly increased (mean $32 \%$ ) on lymphocytes from patients with active SLE $(P<0.05)$. Membrane antigens reacting with absorbed, pepsin-digested antisera were present on both $T$ and $B$ cells but, in most instances, predominated on $\mathrm{T}$ cells. Control observations using absorbed pepsin-digested antisera to normal human lymphocytes or peripheral blood lymphocytes from patients with rheumatoid arthritis showed no similar specificity. SLE patients treated with moderate or high dose corticosteroids or immunosuppressive agents (cytoxan or azathioprine) appeared to lose lymphocyte antigens detected by these reagents. Control studies with other connective tissue disease patients, miscellaneous hospitalized subjects, or normal controls showed low levels of reactivity $(2-5 \%)$. SLE lymphocyte membrane antigens uniquely increased during active disease; this may represent neoantigens or alterations associated with the disease itself.
\end{abstract}

Received for publication 15 February 1979 and in revised form 4 October 1979.

\section{INTRODUCTION}

Patients with systemic lupus erythematosus (SLE) ${ }^{1}$ frequently have cold-reactive serum lymphocytotoxic antibodies (1-4), which are detected by various modifications of the original microcytotoxicity test (5); these antibodies appear to be mainly immunoglobulin (Ig) $\mathrm{M}$ but probably represent only part of a broad spectrum of anti-lymphocyte responses present in patients with SLE (6-9). Anti-lymphocyte antibodies associated with active SLE show varying degrees of reactivity for lymphocyte subpopulations. Thus, whole serum or IgG fractions of some SLE sera are capable of blocking mixed leukocyte culture reactivity by interaction with responder lymphocyte populations $(10,11)$. In addition, reactions with both $\mathrm{T}$ and $\mathrm{B}$ lymphocytes have been detected using other techniques $(8,12,13)$. One possible explanation for the original genesis of antilymphocyte antibody in SLE serum might be that intrinsic alterations in lymphocyte membranes could be induced by the disease itself (14). If, for instance, a virus was resident within SLE lymphocytes, it might induce an immune response by coding for alterations in various cell surface membrane structures. Such a circumstance might favor production of anti-lymphocyte antibody with specificity for altered autologous membrane components but with cross-reactivity for normal lymphocyte cell surface structures. Alternative possibilities are that SLE anti-lymphocyte antibodies recognize derepressed gene products or idiotypic antigens on expanded clones of antigen-reactive lympho-

${ }^{1}$ Abbreviations used in this paper: ALL, acute lymphoblastic leukemia; E, erythrocyte; FACS, Fluorescence-Activated Cell Sorter; Fc crystalline fragment; PMN, polymorphonuclear leukocyte; RA, rheumatoid arthritis; SLE, systemic lupus erythematosus. 
cytes in SLE. Examination of these possibilities is made difficult by the broad heterogeneity of antibodies in SLE; we have therefore adopted a different approach and have sought direct evidence for the existence of new or altered antigens on SLE lymphocytes by heteroimmunization. A general approach was used for immunizing against weak cell surface antigens that has previously been successful in defining antigens associated with acute lymphoblastic leukemia (15-17). The results presented here provide preliminary evidence for the presence of unusual SLE lymphocyte membrane antigens which may be related to the disease process itself.

\section{METHODS}

Peripheral blood samples were collected in preservative-free heparin from 48 patients with active SLE as judged by presence of high DNA-binding, low total serum hemolytic complement, clinical evidence of renal or central nervous system involvement, active skin lesions, arthritis or tendonitis, or generalized polyserositis. All patients met preliminary Arthritis Rheumatism Association criteria (18) for a definite diagnosis of SLE. Although no evidence was available at the beginning of the study to the contrary, a conscious attempt was made to avoid collection of blood samples from more than a few patients receiving high dose $(>20 \mathrm{mg} / \mathrm{d})$ prednisone or other corticosteroids or from patients who had been maintained on other immunosuppressive regimes such as azathioprine, cyclophosphamide, or chlorambucil. The degree of clinical activity was arbitrarily graded as mild, moderate, or severe on the basis of concurrent clinical and laboratory findings. Thus, patients classified as showing severe activity manifested fever, multisystem involvement, significant leukopenia (leukocyte count $<3,500$ ) and synovitis, active central nervous system signs, or active nephropathy. Patients with moderate involvement showed no fever or ongoing evidence of multisystem involvement but showed clinical and laboratory signs of activity in at least one major system such as nephropathy, thrombocytopenia, central nervous system involvement, or synovitis. SLE patients with mild activity showed only episodic, symptomatic minor flares of disease usually without concurrent marked change in serum complement profile, DNA binding, or ancillary laboratory parameters. Over half $(27 / 48)$ of the patients studied were regarded as showing severe involvement and 19 were studied before any therapy was administered.

Control groups studied included 25 normal subjects of both sexes (ages 20-50 yr) as well as a group of patients with other connective tissue diseases including 24 with rheumatoid arthritis, 4 with mixed connective tissue disease, 5 with scleroderma, 1 with polymyositis, and 1 with periarteritis nodosa. In addition, 21 miscellaneous patients (ages $22-80 \mathrm{yr}$ ) of both sexes representing a number of common medical problems such as myocardial infarction, obstructive lung disease, diabetes, viral pneumonia, pulmonary infarction, alcoholic liver disease, tuberculosis, or gonococcal sepsis were also studied.

Lymphocytes were isolated from blood samples using Ficoll (Pharmacia Fine Chemicals, Div. of Pharmacia Inc., Piscataway, N. J.)-triosil density sedimentation (19), and depleted of monocytes and adherent cells by incubation at $37^{\circ} \mathrm{C}$ for $45 \mathrm{~min}$ on glass petri dishes as previously described (20). This procedure also allowed for shedding of any cytophilic Ig passively absorbed to the test cells. In some experiments, lymphocytes were separated into erythrocyte $(E)$-rosetting and nonrosetting subpopulations using neuraminidase $\mathrm{E}$ rosettes and centrifugation through a Ficoll-triosil gradient as previously described (21). Nonrosetting cells at the Ficoll-triosil interface were almost entirely B and "null" cells as indicated by fluorescence staining for surface immunoglobulin using pepsin-digested rabbit anti-human immunoglobulin (21) as well as by staining with chicken anti-human Ia antibody followed by goat anti-chicken $\gamma$-globulin fluoresceinated antibody $(22,23)$. When neuraminidase E-rosetting $T$ cells and nonrosetting cells were studied for reactivity with various rabbit anti-SLE antisera, test cells were always incubated at $37^{\circ} \mathrm{C}$ in RP.MI medium and $5 \% \mathrm{CO}_{2}$-air overnight to allow for complete shedding of any traces of adherent autologous (ytophilic anti-lymphocyte antibody before testing.

Polymorphonuclear leukocytes (P.MN) from both normal control and SLE patients were obtained using dextran sedimentation of whole blood. P.MN-rich cell populations contained $>90 \%$ granulocytes. The pellet of fresh PMN was incubated with various anti-SLE antisera for $30 \mathrm{~min}$ either at $4^{\circ}$ or $37^{\circ} \mathrm{C}$, the cells were washed, and then the fluoresceinlabeled goat $\mathrm{F}(\mathrm{ab})_{2}{ }^{\prime}$ anti-rabbit IgG $\mathrm{F}(\mathrm{ab})_{2}^{\prime}$ was applied for staining. In most instances fresh PMN were also studied after collection in heparinized tubes maintained on ice at $4^{\circ} \mathrm{C}$ to which $0.02 \%$ sodium azide had been added to abrogate in vitro phagocytosis which might occur during cell preparation and handling. In these latter instances all subsequent phases of PMN preparation, washing, and staining were carried out at $4^{\circ} \mathrm{C}$.

Production of antisera against SLE lymphocytes. Rabbits were immunized with pooled lymphocytes from 25 acutely ill SLE patients who were not receiving corticosteroids or other immunosuppressive medications. Advantage was taken of therapeutic plasmapheresis procedures being undertaken in six such patients to secure large quantities of lymphocytes $\left(200-800 \times 10^{6}\right.$ cells at a time). These mononuclear cells were washed in RPMI 1640 medium at $37^{\circ} \mathrm{C}$ and subsequently allowed to elute possible adsorbed cytophilic antibodies at $37^{\circ} \mathrm{C}$ in 5\% $\mathrm{CO}_{2}$-air for 3-4 h. After a final washing at room temperature $\left(22^{\circ} \mathrm{C}\right)$, aliquots of these freshly prepared lymphocytes were frozen using a programmed cell-freezing unit which cooled cells at $2^{\circ} \mathrm{C} / \mathrm{min}$ down to $-197^{\circ} \mathrm{C}$ before they were stored in liquid nitrogen with $10 \%$ dimethyl sulfoxide and $10 \%$ fetal calf serum. In addition, individual smaller quantities $\left(2-10 \times 10^{6}\right)$ of lymphocytes obtained from in-patients or out-patients during active stages of SLE were similarly processed and stored frozen in liquid nitrogen. When sufficient quantities of SLE lymphocytes had been accumulated from a total of 25 patients with SLE, a series of three intravenous injections of $300-420 \times 10^{6}$ SLE lymphocytes were administered at $7-10$-d intervals to a total of three rabbits. Each rabbit received living SLE lymphocytes from at least 10 SLE donors. Immediately before each intravenous injection, previously frozen viable cells were brought quickly to room temperature, washed twice in RPMI medium, and incubated for $30 \mathrm{~min}$ at $37^{\circ} \mathrm{C}$ with heat-inactivated rabbit antiserum to normal human thymus and antiserum to normal human tonsils, using $0.5 \mathrm{ml}$ rabbit antiserum $/ 200 \times 10^{6}$ lymphocytes. The viability of cells previously stored frozen was high with 85-90\% showing exclusion of the supravital dyes trypan blue and eosin Y. Thus, rabbits were immunized with antibody-coated SLE mononuclear cells. No washing of antibody-coated lymphocytes was performed before injection and the pooled SLE lymphocytes along with the mixture of rabbit anti-human thymus and rabbit anti-normal human tonsil was slowly administered intravenously to rabbits over the course of $3 \mathrm{~min}$. This general method is similar to that previously used for production of antiserum to the acute lymphoblastic leukemia (ALL) antigen $(15,16) .1$ wk after the third injection of pooled SLE lymphocytes, rabbits were bled out and antiserum absorbed. 
Control immunizations were conducted in identical protocols using lymphocytes isolated from fresh normal human tonsils after mincing, filtration through wire mesh, and extensive washing with Hanks' balanced salt solution. 300-400 $\times 10^{6}$ living tonsillar lymphocytes were used for each of a series of three weekly intravenous injections. Again normal tonsillar lymphocytes were precoated with rabbit antiserum to normal tonsils and normal human thymus before intravenous immunizations. A second control group of immunizations included similar numbers of peripheral blood lymphocytes obtained from at least 10 different patients with active rheumatoid arthritis (RA). Cells from RA patients were collected, stored after freezing in a programmed cell freezer, and later pooled to provide batches of cells used for intravenous immunizations of three rabbits. All pools of RA lymphocytes were precoated with rabbit antibody to normal human tonsillar cells and human thymocytes before intravenous immunizations.

Absorption procedures. Antisera were first inactivated at $56^{\circ} \mathrm{C}$ for $30 \mathrm{~min}$. They were then absorbed 4 times with onethird volume of freshly washed human $A B$ erythrocytes, $7-10$ times with one-third volume of freshly prepared washed human tonsillar lymphocytes, and 2-3 times with one-third volume of human thymus cells obtained from fresh samples of thymus removed during cardiac surgery, and twice with normal peripheral blood lymphocytes. Antisera were also absorbed twice with one-third volume of washed leukocytes from patients with chronic granulocytic leukemia, once with lymphocytes from patients with chronic lymphatic leukemia, and once with cells from patients with myelogenous leukemia in blast crisis. All absorptions were carried out at $4^{\circ} \mathrm{C}$ for $2-4 \mathrm{~h}$ with frequent agitation of cell pellets to mix absorbing cells with antiserum. Toward the end of these extensive absorption procedures, absorbing cells were monitored by indirect immunofluorescence using fluorescein-labeled goat anti-rabbit $\gamma$-globulin to detect surface rabbit IgG still being absorbed out by the respective absorbent cell preparations.

After absorption appeared complete and no more rabbit Ig was detected on absorbing cells by indirect immunofluorescence, whole antisera were then digested with pepsin at $\mathrm{pH}$ 4.0 to produce $\mathrm{F}(\mathrm{ab})_{2}{ }^{\prime}$ fragments devoid of $\mathrm{Fc}$. Completeness of peptic digestion was monitored using acrylamide gel electrophoresis, Ouchterlony analysis with specific goat anti-rabbit Fc antibody, and absorption with whole Cowan I staphylococcal organisms containing protein A, or with protein A linked to Sepharose. Whole absorbed antiserum was pepsin digested at $\mathrm{pH} 4.0,37^{\circ} \mathrm{C}$, using $2 \mathrm{mg}$ pepsin $/ \mathrm{ml}$ of whole serum. After $14 \mathrm{~h}$ of pepsin digestion, the precipitate was pelleted in the ultracentrifuge by centrifugation at $20,000 \mathrm{~g}$ for $30 \mathrm{~min}$, and supernates were redigested with pepsin a second time again using $2 \mathrm{mg} / \mathrm{ml}$ serum over a 10 -h period. At the end of the second digestion, insoluble precipitate was again cleared by ultracentrifugation. The supernate containing $\mathrm{F}(\mathrm{ab})_{2}^{\prime}$ fragments was then dialyzed overnight for $12 \mathrm{~h}$ against $0.005 \mathrm{M}$, pH 7.5, phosphate buffer. After this dialysis step the material was absorbed with protein A linked to Sepharose and cleared in the preparative ultracentrifuge at $100,000 \mathrm{~g}$ using a $10 \times 10$-in. head and the cleared supernate containing $\mathrm{F}(\mathrm{ab})_{2}{ }^{\prime}$ fragments of antibody adjusted to $\mathrm{pH} 7.4$ and 0.1 molarity for use in cell membrane immunofluorescence studies.

Pepsin-digested whole absorbed antisera were incubated with normal or patient lymphocytes or PMN for $30 \mathrm{~min}$ at $22^{\circ} \mathrm{C}$, washed with RPMI medium, and fluorescein-labeled goat $F(a b)_{2}^{\prime}$ fragments of anti-rabbit $F(a b)_{2}^{\prime}$ applied, washed once, and cell preparations mounted under sealed cover slips and examined under incident light using phase and UV immunofluorescence microscopy. The goat $\mathrm{F}(\mathrm{ab})_{2}^{\prime}$ anti-rabbit $\mathrm{F}(\mathrm{ab})_{2}^{\prime}$ antibody had been specifically isolated by affinity chromatography from a solid-phase rabbit $\mathrm{F}(\mathrm{ab})_{2}^{\prime}$ column and only specific eluted antibody labeled with fluorescein. This reagent showed no reactivity with isolated rabbit $\mathrm{Fc}_{\mathrm{c}}$ fragment by Ouchterlony analysis. In all immunofluorescence procedures controls included $\mathrm{F}(\mathrm{ab})_{2}{ }_{2}$ fragments derived from normal rabbit serum as well as application of the fluorescein isothiocyanate-labeled goat $\mathrm{F}(\mathrm{ab})_{2}{ }^{\prime}$ anti-rabbit $\mathrm{F}(\mathrm{ab})_{2}{ }^{\prime}$ alone.

In some cases monocyte and adherent cell-depleted lymphocyte cell populations from both SLE patients and normal controls were studied after separation of large and small mononuclear cells with the Becton, Dickinson Fluorescence-Activated Cell Sorter (FACS-1, Becton, Dickinson FACS Systems, Mountain View, Calif.). The principles and details of the FACS operation have previously been described (24-26). In addition, sorting for intensity of fluorescence and cell profile was also performed using whole Ficoll-triosil lymphocyte preparations from patients with active SLE in comparison to normal controls.

\section{RESULTS}

Studies using absorbed pepsin-digested antisera. After the extensive absorptions noted above, pepsindigested antisera made against SLE lymphocytes from two of the three rabbit antisera appeared to show preferential reactivity for membrane determinants present on mononuclear cells from SLE patients. Some residual staining was noted in a small population of normal control cells studied in parallel; Possible nonspecific background staining was calculated from control experiments where pepsin-digested normal rabbit serum was applied before addition of the fluoresceinlabeled specific goat $\mathrm{F}(\mathrm{ab})_{2}{ }_{2}^{\prime}$ anti-rabbit $\mathrm{F}(\mathrm{ab})_{2}{ }^{\prime}$. In these control experiments, $1.8-5 \%$ of normal, rheumatoid, or test SLE cells showed a low level of apparent background binding. A summary of data obtained in these experiments is given in Table $\mathbf{I}$.

In many of these assays whole monocyte-depleted lymphocytes were tested in parallel with nonrosetting and neuraminidase E-rosetting $\mathrm{T}$ lymphocytes as well as PMN isolated by initial dextran sedimentation before Hypaque-triosil mononuclear cell preparation. All PMN preparations were studied within $<3 \mathrm{~h}$ of initial blood collection. Several interesting points can be noted in the data shown in Table I. In patients 3 and 5, after a 45 -min incubation at $37^{\circ} \mathrm{C}$, relatively low proportions of lymphocytes were stained ( 5 and $17 \%$ ); however, again much higher proportions of lymphocyte subpopulations $(80,56$, and $72 \%)$ showed staining after overnight $37^{\circ} \mathrm{C}$ incubation using the same pepsindigested antisera. Relatively low proportions of cells were noted staining in normal subjects, miscellaneous disease controls, and other connective tissue disease patients studied. Also it appeared that anti-SLE antisera were reacting wth membrane determinants that were present on both nonrosetting and T-rosetting cells. However, in most SLE patients, higher proportions of neuraminidase-rosetting cells showed positive staining. This was particularly striking in patients 4 , 6,12 , and 13 , all of whom were untreated with ex- 
TABLE I

Percentage of Lymphocytes Staining with Whole Pepsin-Digested Absorbed Whole Anti-SLE Lymphocyte Antisera using SLE and Control Patients' Mononuclear Cells

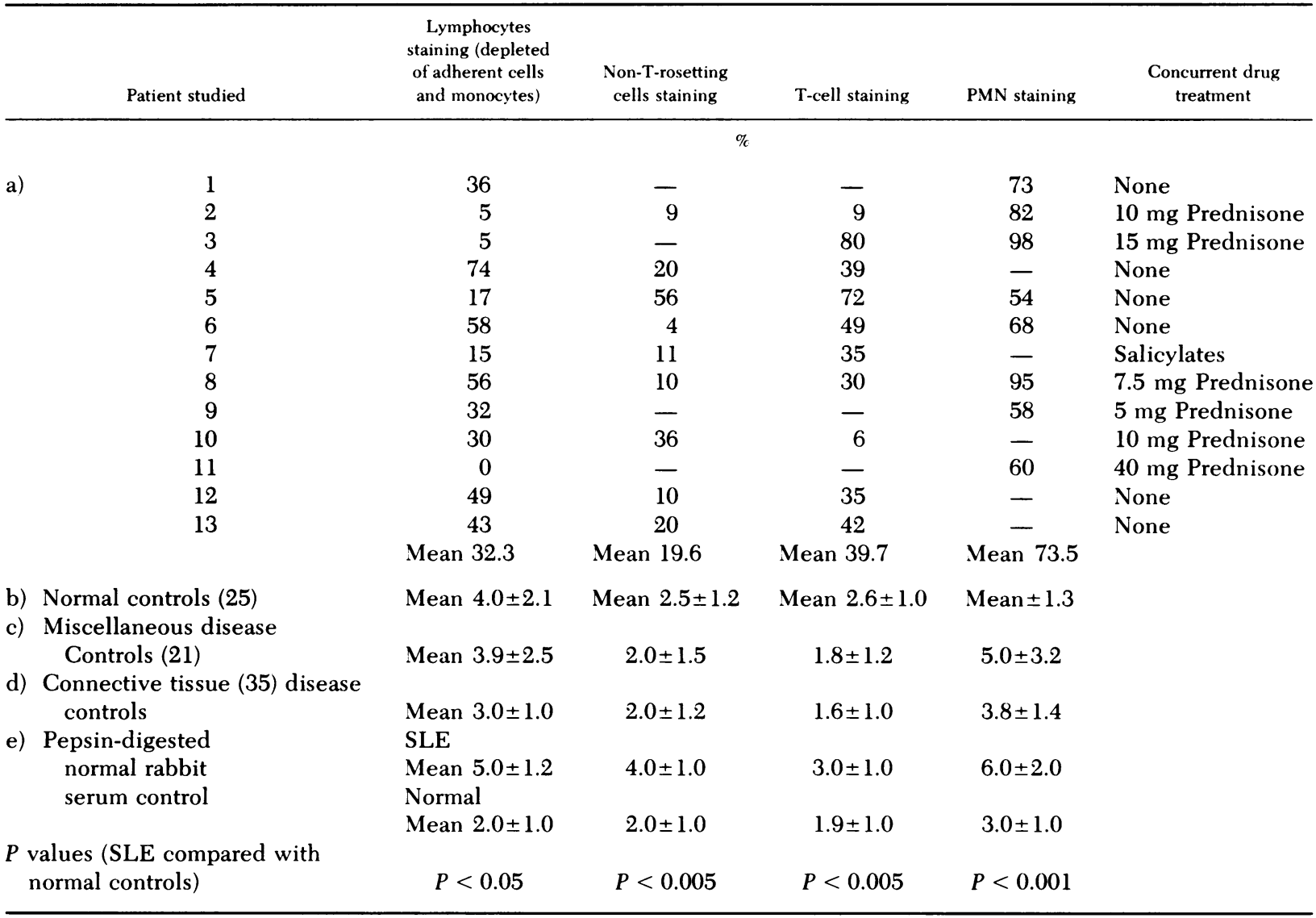

tremely active SLE. On the contrary, patient 10 showed a higher proportion of positively staining cells in the non-T-rosetting fraction. Patient 11, who had received $1-\mathrm{g} / \mathrm{d}$ doses of methyl prednisone during the preceding week and was receiving $40 \mathrm{mg}$ prednisone/d at the time of assay, showed no mononuclear cells reacting with absorbed pepsin-digested antisera.

Control observations using absorbed pepsin-digested antisera to normal human tonsillar lymphocytes and other similarly processed antisera made against pooled RA lymphocytes showed no similar specificity. Pepsindigested absorbed antisera to normal human tonsils produced essentially negative results with 15 normal controls, 12 patients with RA, and 10 patients with active SLE. In similar fashion, no rheumatoid specificity was apparent when three different rabbit antisera against RA lymphocytes absorbed and pepsin digested in similar protocols were studied using SLE, RA, and normal control lymphocytes. A summary of these control experiments is shown in Table II. Data for one anti-RA antiserum shown in (B) was similar to that recorded with two other separate anti-RA lymphocyte antisera.
During the course of these studies it appeared that the reactivity of the absorbed pepsin-digested antiSLE lymphocyte antisera was higher in percentage of cells staining using freshly collected SLE lymphocytes than with cells previously obtained from the same patients and stored frozen for several weeks or months in liquid nitrogen. It was also found that when freshly collected lymphocytes were recovered from Ficoll-triosil and not allowed to elute possible cytophilic antibody at $37^{\circ} \mathrm{C}$, a much lower proportion of positively staining cells was identified. Subsequently after overnight incubation at $37^{\circ} \mathrm{C}$ in $5 \% \mathrm{CO}_{2}$ air, the proportion of positively staining cells increased markedly.

A number of observations appeared to be consistent with a relative loss of positively staining lymphocytes in SLE patients receiving moderate or high doses of corticosteroids. Therefore it was very unusual to see $>10-15 \%$ positively staining lymphocytes in SLE subjects taking over $20 \mathrm{mg}$ prednisone/d. Serial studies in several patients showed decreases from initial percentage positivity of 55-70\% in whole monocyte-depleted lymphocytes during initial active untreated SLE to 10$20 \%$ positive cells within several days after institution 
TABLE II

Control Experiments Using Absorbed Pepsin-digested Rabbit Antisera to Normal Human Tonsillar Lymphocytes and Peripheral Blood Lymphocytes from Patients with RA

\begin{tabular}{|c|c|c|c|c|}
\hline \multirow{2}{*}{\multicolumn{2}{|c|}{ Reagents used }} & \multicolumn{3}{|c|}{$\begin{array}{l}\text { Peripheral blood mononuclear } \\
\text { cells staining, \% }\end{array}$} \\
\hline & & $\begin{array}{c}\text { Normal } \\
\text { controls } \\
\text { (15) }\end{array}$ & $\begin{array}{c}\mathrm{RA} \\
\text { patients } \\
(12)\end{array}$ & $\begin{array}{c}\text { SLE } \\
\text { patients } \\
(10)\end{array}$ \\
\hline & $\mathrm{F}(\mathrm{ab})_{2}^{\prime}$ from antiserum made against normal human tonsils* & 0 & 0 & 0.12 \\
\hline (B) & $\mathbf{F}(\mathrm{ab})_{2}^{\prime}$ from antiserum made against peripheral blood lymphocytes from RA patients* & 0.23 & 0.35 & 0.10 \\
\hline
\end{tabular}

* Pepsin-digested antiserum prepared after whole antiserum was absorbed in an identical protocol as that used for absorption of antisera made against SLE lymphocytes.

of corticosteroid therapy at $40-60 \mathrm{mg}$ prednisone/d. Degree of positivity of lymphocyte staining with pepsindigested absorbed anti-SLE reagents roughly appeared to approximate clinical activity although several exceptions to this rule were recorded.

Definition of cell types reacting with anti-SLE reagents. Lymphocyte cell surface staining was performed on various cell subpopulations in parallel with other lymphocyte membrane antigen assays in an attempt to ascertain whether or not the reagents were reacting with any particular lymphocyte subpopulation. In some experiments E-rosetting and nonrosetting lymphocytes obtained from Hypaque-triosil-isolated cells depleted of monocytes and adherent cells by adherence to petri dishes were studied using twice pepsin-digested $F(a b)_{2}{ }^{\prime}$ fragments of rabbit anti-SLE antisera and double staining using specific chicken antihuman Ia antiserum in conjunction with rhodaminelabeled sheep anti-chicken $\gamma$-globulin. The use of chicken anti-Ia reagents avoided non-specific binding to various cell surface $\mathrm{Fc}$ receptors since chicken Ig was shown in parallel control experiments not to react with human mononuclear cell membrane Fc receptors. ${ }^{2}$ These experiments are shown in Table III. It can be seen that a $20-30 \%$ overlap or double staining with antiSLE and anti-Ia occurred in the non-T-rosetting cell populations from SLE patients; however, there was very little overlap between $\mathrm{Ia}^{+}$cells in the neuraminidase T-rosetting cell population and concurrent staining with $\mathrm{F}(\mathrm{ab})_{2}{ }^{\prime}$ anti-SLE reagents.

Studies with PMN. The staining noted with PMN appeared to be globular and particulate both on the leukocyte surface and throughout the cell. Examples of these staining patterns are shown in Fig. 1. Distribution of PMN immunofluorescence was compatible with ingested complexes or phagocytosed material. In a number of SLE patients, blood was collected in $0.02 \%$

${ }^{2}$ Janossy, G., D. R. Sutherland, and M. F. Greaves. Unpublished observations.

TABLE III

Double Labeling Experiments Aimed at Definition of Lymphocyte Subpopulations Reacting with Absorbed Pepsin-digested Anti-SLE Sera

\begin{tabular}{|c|c|c|c|c|c|c|}
\hline & \multicolumn{3}{|c|}{ Non-T-rosetting cells } & \multicolumn{3}{|c|}{ T-rosetting cells } \\
\hline & $\begin{array}{l}\text { Staining } \\
\text { anti-SLE }\end{array}$ & $\mathrm{Ia}+$ & $\begin{array}{c}\text { Staining } \\
\text { Ia }+ \text { anti-SLE }\end{array}$ & $\begin{array}{l}\text { Anti- } \\
\text { SLE }\end{array}$ & $\begin{array}{c}\text { Staining } \\
+ \text { Ia }\end{array}$ & $\begin{array}{c}\mathrm{Ia}+ \\
\text { anti-SLE }\end{array}$ \\
\hline & & & & & & \\
\hline \multicolumn{7}{|c|}{ SLE patient studied } \\
\hline A & 11 & 48 & 1 & 35 & 5 & 1 \\
\hline B & 32 & 80 & 15 & 30 & 0 & 0 \\
\hline $\mathrm{C}$ & 4 & 67 & 0 & 49 & 4 & 3 \\
\hline D & 24 & 57 & 22 & 72 & 6 & 2 \\
\hline $\mathbf{E}$ & 12 & 59 & 2 & 27 & 3 & 1 \\
\hline $\mathbf{F}$ & 42 & 84 & 33 & 69 & 1 & 0 \\
\hline \multicolumn{7}{|c|}{ Normal controls } \\
\hline 1 & 5 & 70 & 5 & 4 & 2 & 0 \\
\hline 2 & 6 & 65 & 4 & 4 & 3 & 0 \\
\hline 3 & 4 & 80 & 4 & 2 & 3 & 0 \\
\hline 4 & 0 & 85 & 3 & 3 & 1 & 1 \\
\hline
\end{tabular}



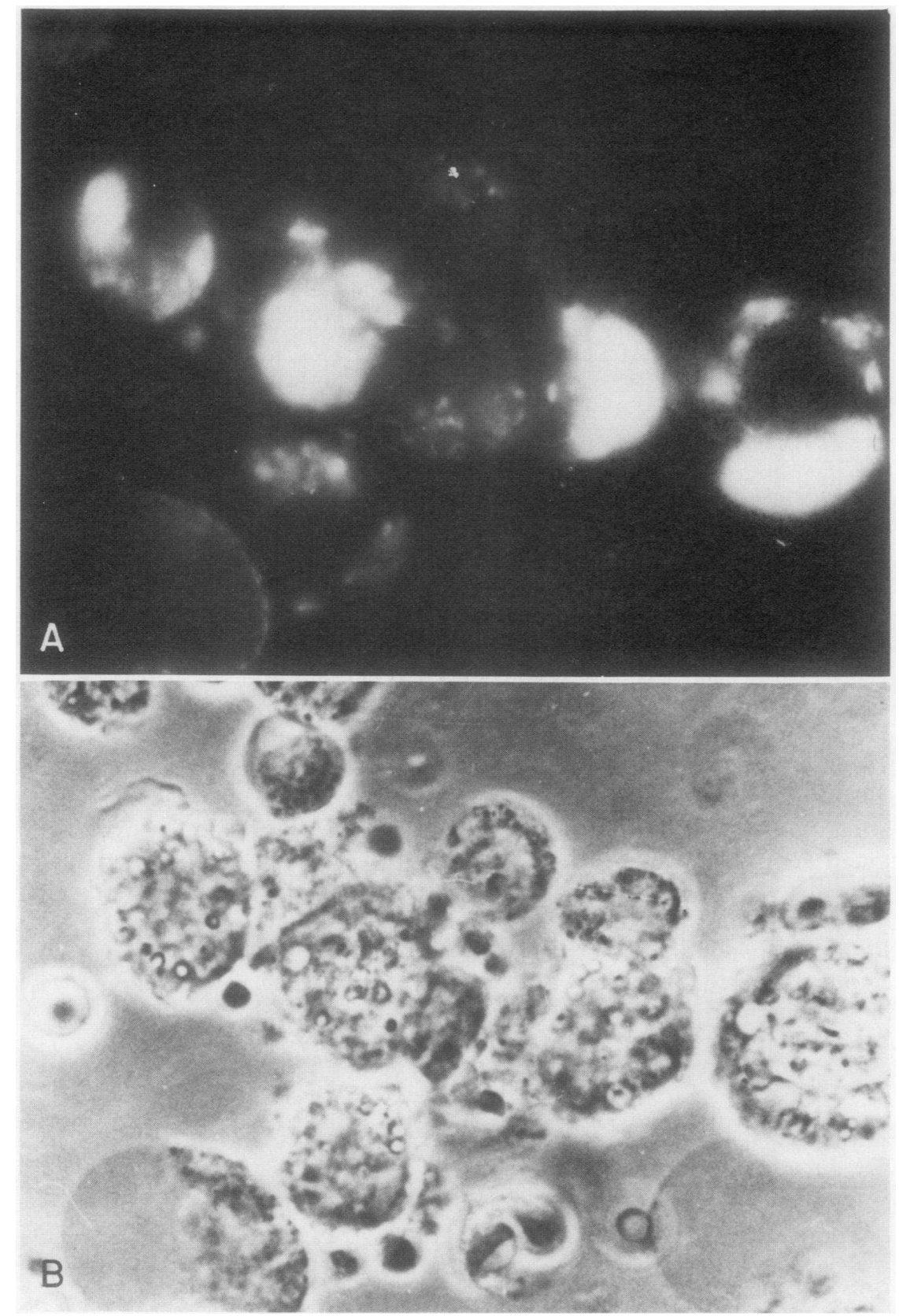

FIGURE 1 (A) Immunofluorescence pattern of staining of PMN with absorbed $\mathrm{F}(\mathrm{ab})_{2}$ ' of anti-SLE lymphocyte antiserum. Large intracellular areas as well as punctate membrane staining are noted. (B) Phase contrast view of same microscopic field as shown above in Fig. 1.

sodium azide and placed immediately on ice at $4^{\circ} \mathrm{C}$. This latter procedure did not affect the proportion of PMN staining with absorbed anti-SLE antisera. Moreover, incubation of normal PMN with fresh SLE plasma at $37^{\circ} \mathrm{C}$ for $30 \mathrm{~min}$ followed by staining showed only slight increment (mean 10\%) in percentage of positive staining cells, but in no instance approximated the 54-98\% PMN staining seen in fresh SLE PMN.
Staining of SLE PMN for Ig using fluorescein-labeled goat $\mathrm{F}(\mathrm{ab})_{2}{ }^{\prime}$ anti-human $\mathrm{F}(\mathrm{ab})_{2}{ }^{\prime}$ showed Ig within a much smaller proportion of SLE PMN studied in parallel. These data indicated that material staining in PMN with absorbed anti-SLE antisera was not a phenomenon ocurring in vitro after removal of blood samples from patients. If material associated with PMN were originally associated with immune complexes, it 
is conceivable that after in vivo ingestion, Ig portions were rapidly degraded by lysosomal enzymes.

Specificity studies. Because the previously absorbed pepsin-digested anti-SLE reagents appeared to identify antigens present both on the membranes of mononuclear cells and on phagocytic PMN, it seemed possible that the specificity of these antisera might be directed at antigens circulating in SLE plasma. Accordingly, pepsin-digested anti-SLE lymphocyte antisera were subsequently absorbed with SLE plasma from four patients using $0.1 \mathrm{ml}$ pooled plasma $/ 0.4 \mathrm{ml}$ cell-absorbed pepsin-digested anti-SLE reagent. After clearing in the ultracentrifuge, no diminution in staining for SLE lymphocytes was noted after these absorption procedures. Moreover, no lines were observed in micro-Ouchterlony experiments between cell-absorbed pepsin-digested anti-SLE antisera and six other active SLE sera.

Absorbed pepsin-digested anti-SLE antisera were next studied using monocyte-depleted lymphocyte preparations from patients with active SLE in comparison to PMN isolated from the same patients. $0.2 \mathrm{ml}$ antiserum was absorbed with $3-5 \times 10^{6}$ lymphocytes or 5 $\times 10^{6} \mathrm{PMN}$ collected initially on ice at $4^{\circ} \mathrm{C}$. Membrane staining of lymphocytes was markedly reduced both in intensity and proportion of cells staining using two absorptions at $4^{\circ} \mathrm{C}$ for $3 \mathrm{~h}$ with SLE lymphocytes; in addition marked reduction of staining PMN occurred after lymphocyte absorption of antisera. Conversely, parallel absorption of pepsin-digested antiserum with PMN also reduced staining for both lymphocytes and PMN. Results of two separate experiments are summarized in Table IV. It appeared that antigens recognized by the anti-SLE antisera were more easily removed by absorption with lymphocytes than with PMN.

TABLE IV

Absorption Experiments Using Pepsin-digested, Absorbed Anti-SLE Lymphocyte Antisera

\begin{tabular}{ccc}
\hline & After absorption & \\
Before & with SLE & With SLE \\
absorption & lymphocytes* & PMN $\downarrow$ \\
\hline
\end{tabular}

Experiment 1

SLE lymphocytes

staining

SLE PMN staining
35

60
Experiment 2

SLE lymphocytes

staining

SLE PMN staining

\section{2}

33
2

8
10

28
* Absorption with normal donor lymphocytes did not materially affect proportions or intensity of fluorescence. \$ Absorption with normal PMN did not alter immunofluorescence.
Studies with cell lines. The experiments described above indicated that the extensively absorbed anti-SLE reagents reacted with both E-rosetting and nonrosetting cells from peripheral blood of SLE subjects. A number of human cell lines were also tested for reactivity with the same anit-SLE reagents. Results of these experiments are shown in Table V. Of interest was the relatively high proportion of cells $(22 \%)$ staining in one T-(ALL) cell line (CCRF/CEM). However, controls with pepsin-digested normal rabbit IgG were high $(9 \%)$ with this line. No significant increment in staining was noted with either $\mathrm{Ia}^{+} \mathrm{B}$-cell lines or the lines REH and NALM-6-1 originally obtained from patients with non-T and non-B ALL (27).

Studies on SLE renal biopsy tissue. One of the patients showing high proportions (58\%) of cells staining with absorbed pepsin-digested anti-SLE lymphocyte serum underwent renal biopsy during the time of the study. An opportunity was therefore afforded for direct examination of fresh renal tissue in this patient. These studies were performed in conjuction with routine immunofluorescence using anti-C3, anti-IgG, IgA and IgM which showed only traces of glomerular immune deposits in parallel with apparently normal conventional microscopic appearance in glomeruli included within the biopsy core. In several areas, however, hematoxylin and eosin stains showed significantly increased interstitial renal accumulations of lymphocytes. Application of pepsin-digested absorbed anti-SLE lymphocyte antiserum followed by fluorescein-conjugated $\mathrm{F}(\mathrm{ab})_{2}{ }_{2}^{\prime}$ goat anti-rabbit $\mathrm{F}(\mathrm{ab})_{2}{ }^{\prime}$ showed staining of $80 \%$ of these interstitial renal lymphocyte accumulations. No significant staining of glomeruli, renal tubular cells, or discrete areas in conjunction with the traces of glomerular immune deposits was noted. Double staining of renal interstitial lymphoid infiltrates using rhodamine-conjugated sheep anti-chicken $\gamma$-globulin and chicken anti-human Ia in parallel with rabbit antiSLE lympocyte $\mathrm{F}(\mathrm{ab})_{2}{ }^{\prime}$ and fluorescein-labeled $\mathrm{F}(\mathrm{ab})_{2}{ }^{\prime}$ goat anti-rabbit $\mathrm{F}(\mathrm{ab})_{2}{ }^{\prime}$ indicated that $25 \%$ of the positively staining lymphoid cells reacting with the absorbed anti-SLE lymphocyte reagent were also $\mathrm{Ia}^{+}$.

Attempts were also made to stain renal biopsy frozen sections on four SLE patients with lupus nephropathy who had undergone kidney biopsies in the recent past where frozen material was still available for examination. Sections were overlaid with pepsin-digested whole absorbed anti-SLE antiserum, washed, and stained with fluorescein isothiocyanate $F(a b)_{2}{ }^{\prime}$ antirabbit $F(a b)_{2}{ }^{\prime}$. Although all of these latter sections showed immune deposits characterized by glomerular Ig and C granular immunofluorescence, no staining of immune deposits or other areas was noted with the anti-SLE reagents.

FACS analysis. The FACS was used in a number of experiments to obtain an analysis of the general size 
TABLE V

Reactivity by Indirect Immunofluorescence of Absorbed Anti-SLE

Reagents with Various Human Cell Lines

\begin{tabular}{|c|c|c|c|c|c|c|c|c|}
\hline \multirow[b]{2}{*}{ Cell line tested } & \multicolumn{6}{|c|}{ Cell phenotypic markers } & \multirow{2}{*}{$\begin{array}{c}\text { Staining } \\
\text { with } F(a b)_{2}^{\prime} \\
\text { anti-SLE } \\
\gamma \text {-globulin }\end{array}$} & \multirow{2}{*}{$\begin{array}{c}\text { Staining } \\
\text { with } \mathrm{F}(\mathrm{ab})_{2}^{\prime} \\
\text { normal rabbit } \\
\gamma \text {-globul in }\end{array}$} \\
\hline & $\begin{array}{c}\text { Ia-like } \\
\text { ag }\end{array}$ & Sin Ig* & $\begin{array}{c}\text { Tdt } \\
\text { enzyme }\end{array}$ & $\mathrm{E}$ & $\begin{array}{c}\text { HuTL } \\
\text { ag }\end{array}$ & $\begin{array}{c}\mathrm{ALL} \\
\mathrm{ag}\end{array}$ & & \\
\hline & & & & & & & $\%$ & $\%$ \\
\hline \multicolumn{9}{|l|}{ B-cell lines } \\
\hline Raji & + & + & 0 & 0 & & & 7 & 3 \\
\hline Bri-7 & ++ & + & 0 & 0 & & & 1 & 2 \\
\hline NC 37 & + & + & 0 & ) & & & 6 & 6 \\
\hline Riva & + & + & 0 & 0 & & & 5 & 4 \\
\hline \multicolumn{9}{|l|}{$\mathrm{T}$-cell lines } \\
\hline MOLT-4 & - & () & + & + & ++ & & 6 & 0 \\
\hline CCRF CEM & - & 0 & + & + & ++ & & 22 & 9 \\
\hline CCRF-SB & - & 0 & + & + & ++ & & 11 & 0 \\
\hline HPB-MLT & - & 0 & + & + & ++ & & 3 & 0 \\
\hline 8402 & - & 0 & + & + & ++ & & 2 & 0 \\
\hline \multicolumn{9}{|l|}{ Stem-cell lines } \\
\hline REH & ++ & 0 & +++ & 0 & 0 & ++ & 0 & 0 \\
\hline NALM-6-11 & ++ & 0 & +++ & 0 & 0 & ++ & 3 & 2 \\
\hline
\end{tabular}

* SmIg, surface immunoglobulin.

and profile of whole mononuclear cells without monocyte depletion from SLE patients reacting with the $\mathrm{F}(\mathrm{ab})_{2}{ }^{\prime}$ anti-SLE lymphocyte reagents. In these analyses, the cell profile of size distribution was adjusted to test only the smallest $30 \%$ of mononuclear cells in parallel with the largest $15 \%$ of the same cell population. In several individual analyses $60-80 \%$ of the small lymphocyte fraction from SLE patients showed definite positive staining, whereas $40-60 \%$ of the largest cells showed positive reactions. Cytologic examination showed that this latter population was contaminated with 20-30\% monocyte-appearing cells and PMN. These experiments provided clear evidence for the presence of positively reacting membrane antigens on small lymphocytes from SLE patients. In addition, FACS analysis was made using lymphocytes depleted of monocytes and adherent cells in parallel with similar cell preparations from normal controls. These experiments provided objective data indicating that a considerably higher proportion of lymphocytes from active SLE patients showed staining than was detected in normal controls. Representative experiments of this type are illustrated in Fig. 2.

\section{DISCUSSION}

The present studies indicate that after extensive absorptions, certain antisera raised against lymphocytes from patients with active SLE show apparent reactivity with membrane antigens on SLE lymphocytes but with little or no staining of lymphocytes from patients with other connective tissue diseases including RA, scleroderma, mixed connective tissue disease, or with a variety of other miscellaneous disease controls. No similar staining was noted with pepsin-digested absorbed antisera prepared against normal human tonsillar lymphocytes nor with antisera made against pooled lymphocytes from patients with RA. Moreover, staining which appeared to be unique for membrane determinants on SLE lymphocytes could be specifically absorbed by isolated lymphocytes from SLE subjects but not by normal or other connective tissue disease lymphocytes. Some diminution of staining was also afforded by absorption of anti-SLE antisera with PMN but lymphocytes were more effective than PMN in absorbing out anti-SLE activity.

It seems unlikely that staining activity of the rabbit anti-SLE lymphocyte antibodies produced by these procedures could be accounted for by anti-HLA activity, since no resultant specificity for the immunizing cells could be detected and low or negative values for staining were noted in a large number of controls. Expression of lymphocyte membrane antigens was particularly high $(40-70 \%)$ in some patients with untreated active SLE. Subsequent decrease in proportions of positive cells after corticosteroid or immunosuppressive therapy also appears to argue against any direct HLArelated antigen.

One of the most important problems related to the studies presented here lies in the technical difficulties associated with the presence of $F c$ receptors on a number of mononuclear cell populations $(28-32)$. Care was 

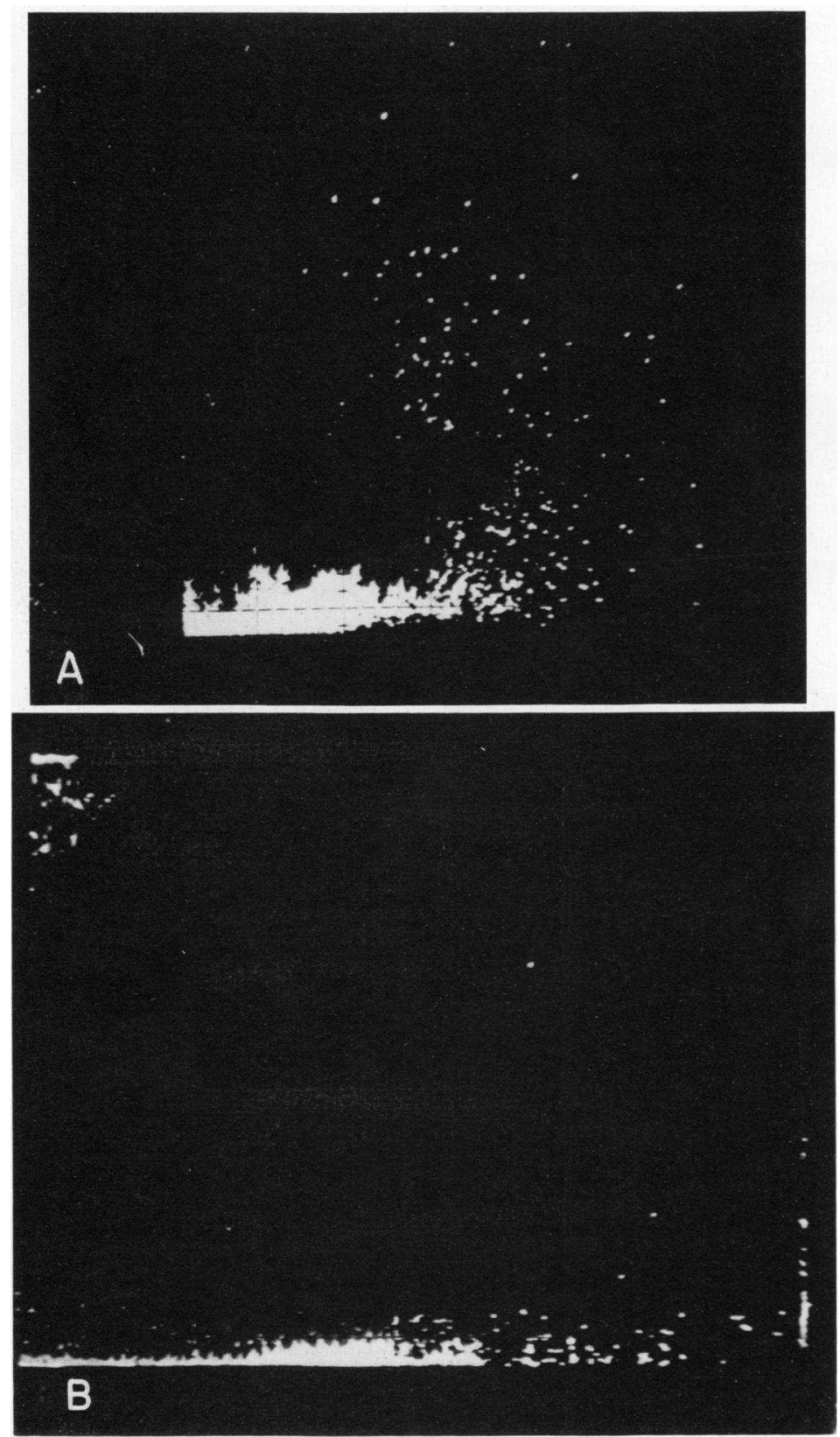

FIGURE 2 (A) FACS analysis of monocyte-depleted lymphocytes from patient with active SLE stained with absorbed $\mathrm{F}(\mathrm{ab})_{2}{ }^{\prime}$ anti-SLE lymphocyte antisera. Cell size increases from left to right. Degree of intensity of fluorescence increases from bottom to top of pattern. (B) FACS analysis of normal control monocyte-depleted lymphocytes showing only a few cells exhibiting staining with absorbed $F(a b)_{2}{ }^{\prime}$ anti-SLE reagent.

taken to clear pepsin-digested absorbed antisera by ultracentrifugation and by absorption with protein $\mathrm{A}$ containing organisms or protein A linked to Sepharose. It is possible that pepsin-digestion itself produced an inadvertent loss in biologic activity of the treated antibodies. Using rabbit allotype-anti-allotype complexes Winfield et al. (33) have recently studied populations of normal human lymphocytes bearing Fc receptors and could account for up to $33 \%$ of cells bearing Fc receptors in normal human peripheral blood. Actually a decrease in $\mathrm{Fc}$ receptor-positive lymphocytes during the course of active SLE has been reported $(34,35)$.

Whether or not some of the SLE cells staining with pepsin-digested absorbed antisera may in fact repre- 
sent an increase in lymphocyte binding through receptors for $\mathrm{F}(\mathrm{ab})_{2}{ }^{\prime}$ at present is not clear. After peptic digestion of absorbed anti-SLE antisera, there still appeared to be preferential staining of anti-SLE reagents for SLE lymphoid cells. Some of this staining could conceivably be related to binding of $F(a b)_{2}{ }^{\prime}$ fragments to the recently described receptor for the latter on normal lymphoid cells (36). However, control observations using identically absorbed and pepsin-digested antisera to both normal human tonsillar lymphocytes and pooled cells from RA patients did not show similar specificity or increased proportions of positive staining with SLE lymphocytes.

Double marker studies indicated that SLE-reactive membrane antigens were present on both $\mathrm{B}$ and $\mathrm{T}$ cells, but that in many instances $\mathrm{T}$-cell fractions showed a higher degree of reactivity than did non-Trosetting cells or B cells as monitored by concurrent anti-Ia and rhodamine staining. Presently there is no evidence that the lymphocyte membrane antigen(s) detected with the extensively absorbed anti-SLE antisera described here have any relationship to virus or cell surface determinants related to any viral genome (37-40). Considerably more work will be necessary before such a possibility can be resolved.

Recent observations by Curd et al. (41) may have some relevance to the findings reported in this study. Presence of a neoantigen of the membrane attack complex of human complement was identified on peripheral blood lymphocytes as well as PMN in patients with SLE. Because the antigen identified by Curd et al. (41) appeared to predominate on granulocytes, such a circumstance could explain our findings of staining a high proportion of PMN in patients with active SLE. Further studies including attempts to block the reactions produced by our antisera with unlabeled antisera reacting with complement neoantigens will be necessary before this question can be resolved. Thus far absorption studies have not provided any direct evidence for different antigens detected by the anti-SLE antisera on lymphocytes and PMN. Absorption with SLE lymphocytes markedly reduced or virtually eliminated lymphocyte membrane staining whereas, PMN staining was also reduced but not as dramatically. Conversely using SLE PMN for absorption, considerable reduction in staining of both lymphocytes and PMN was recorded. If material within the PMN was derived from lymphocyte fragments in vivo, it may well be that PMN used as absorbents were not as efficient or sterically hindered by presence of antigens within confines of cell membranes.

From a different standpoint, it is also conceivable that the lymphocyte cell surface antigens recognized by the highly absorbed anti-SLE lymphocyte antisera were reacting with essentially normal cell surface antigens either increased in density on SLE lymphocyte membranes or altered antigenically as a result of the disease. Further investigation of the specificity of antiSLE lymphocyte sera with respect to these various possibilities now requires immunochemical isolation of the cell surface molecules involved.

\section{ACKNOWLEDGMENT}

This work was supported by grants A.M AI 13824-09 and AM 13690-08 from the National Institute of Health and in part by grants from the Kroc Foundation, Lael Richards Memorial Fund, and the Josiah Macy Foundation.

\section{REFERENCES}

1. Mittal, K. K., R. D. Rossen, J. T. Sharp, M. D. Lidsky, and W. T. Butler. 1970. Lymphocyte cytotoxic antibodies in systemic lupus erythematosus. Nature (Lond.). 225: 12551256.

2. Terasaki, P. I., V. D. Mottironi, and E. V. Barnett, 1970. Cytotoxins in disease Autocytotoxins in lupus. N. Engl. J. Med. 283: 724-728.

3. Butler, W. T., J. T. Sharp, R. D. Rossen, M. D. Lidsky, K. K. Mittal, and D. A. Gard. 1972. Relationship of the clinical course of systemic lupus erythematosus to the presence of circulating lymphocytotoxic antibodies. Arthritis Rheum. 15: $231-238$.

4. Stastny, P., and M. Ziff. 1971. Antibodies against cell membrane constituents in systemic lupus erythematosus and related diseases. I. Cytotoxic effect of serum from patients with systemic lupus erythematosus (SLE) for allogeneic and for autologous lymphocytes. Clin. Exp. Immunol. 8: 543-550.

5. Mittal, K. K., M. R. Micky, D. P. Singal, and P. I. Terasaki. 1968. Serotyping for homotransplantation. XVIII. Refinement of microdroplet lymphocyte cytotoxicity test. Transplantation (Baltimore). 6: 913-927.

6. Winfield, J. B., R. J. Winchester, P. Wernet, S. M. Fu, and H. G. Kunkel. 1975. Nature of cold-reactive antibodies to lymphocyte surface determinants in systemic lupus erythematosus. Arthritis Rheum. 18: 1-8.

7. Husby, G., and R. P. Messner. 1977. Detection of antilymphocyte antibodies in patients with systemic lupus erythematosus by indirect immunofluorescence on acetone-fixed lymphocytes. J. Lab. Clin. Med. 80: 240-249.

8. Williams, R. C., Jr., A. D. Bankhurst, and J. D. Montano. 1976. IgG anti-lymphocyte antibodies in SLE detected by ${ }^{125}$ I protein A. Arthritis Rheum. 19: 1261-1270.

9. Glinski, W., M. E. Gershwin, and A. D. Steinberg. 1976. Fractionation of cells on a discontinuous Ficoll gradient. Study of subpopulations of human T cells using anti-T-cell antibodies from patients with systemic lupus erythematosus. J. Clin. Invest. 57: 604-614.

10. Wernet, P., and H. G. Kunkel. 1973. Antibodies to a specific surface antigen on $T$-cells in human sera inhibiting mixed leukocyte culture reactions. J. Exp. Med. 138: $1021-1026$.

11. Williams, R. C., Jr., R. B. Lies, and R. P. Messner. 1973. Inhibition of mixed leukocyte culture response by serum and $\gamma$-globulin fractions from certain patients with connective tissue disorders. Arthritis Rheum. 16: 597-605.

12. Lies, R. B., R. P. Messner, and R. C. Williams, Jr. 1973. Relative $\mathrm{T}$-cell specificity of lymphocytotoxins from patients with systemic lupus erythematosus. Arthritis Rheum. 16: 369-375.

13. Messner, R. P. 1975. Naturally occurring anti-lymphocyte 
antibodies. In Lymphocytes and Their Interactions. R. C. Williams, Jr., editor. Raven Press, New York. 169-181.

14. Winfield, R. B., R. J. Winchester, and H. G. Kunkel. 1975. Association of cold-reactive anti-lymphocyte antibodies with lymphopenia in systemic lupus erythematosus. Arthritis Rheum. 18: 587-594.

15. Brown, G., N. Hogg, and M. F. Greaves. 1975. Candidate leukemia specific antigen in man. Nature (Lond.). 258: 454-456.

16. Greaves, M. F., G. Brown, N. Rapson, and T. A. Lister. 1975. Antisera to acute lymphoblastic leukaemia. Clin. Immunol. Immunopathol. 3: 461-470.

17. Greaves, M. F., G. Janossy, M. Roberts, N. T. Rapson, R. B. Ellis, J. Chessels, T. A. Lister, and D. Catovsky. 1977. Membrane phenotyping: diagnosis, monitoring and classification of acute 'Lymphoid' leukemias. Haematol. Blood Transfusion. 20: 61-74.

18. Cohen, A., and J. J. Canoso. 1972. Criteria for the classification of systemic lupus erythematosus status. Arthritis Rheum. 15: 540-543.

19. Bøyum, A. 1968. Separation of leukocytes from blood and bone marrow. Scand. J. Clin. Lab. Invest. 21(Suppl); 97.

20. Bankhurst, A. D., and R. C. Williams, Jr. 1975. Identification of DNA-binding lymphocytes in patients with systemic lupus erythematosus. J. Clin. Invest. 56: 13781385.

21. Williams, R. C., Jr., K. A. Kilpatrick, M. Kassaby, and Z. H. Abdin. 1978. Lymphocytes binding C-reactive protein during acute rheumatic fever. J. Clin. Invest. 61: 13841393.

22. Greaves, M. F. 1975. Clinical applications of cell surface markers. Prog. Hematol. 9: 255-303.

23. Janossy, G., A. H. Goldstone, D. Capellaro, M. D. Greaves, J. Lukenkampff, M. Pippard, and K. Welsh. 1977. Differentiation linked expression of p. 28, 33 (Ia-like) structures on human leukemic cells. Br. J. Haematol. 37: 391-402.

24. Loken, M. R., and L. A. Herzenberg. 1975. Analysis of cell populations with a fluorescence-activated cell sorter. Ann. N. Y. Acad. Sci. 254: 163-171.

25. Herzenberg, L. A., R. G. Sweet, and L. A. Herzenberg. 1976. Fluorescence-activated cell sorting. Sci. Am. 234(3): 108.

26. Greaves, M. F., D. Capellaro, G. Brown, T. Revesz, G. Janossy, T. A. Lister, M. Beard, N. Rapson, and D. Catovsky. 1976. Analysis of human leukaemic cells using surface binding probes and the fluorescence activated cell sorter. In Modern Trends in Human Leukemia II. R. Neth, R.C. Gallo, K. Mannweiler, and W.C. Moloney, editors. J. F. Lehmanns, Verlag, Munich. 243.

27. Minowada, J., T. Tsubota, M. F. Greaves, and T. R. Walters. 1977. A non-T, non-B human leukemia cell line (NALM-1): establishment of the cell line and presence of leukemia-associated antigens. J. Natl. Cancer Inst. 59: 83-87.

28. Huber, H., and H. H. Fudenberg. 1968. Receptor sites of human monocytes for IgG. Int. Arch. Allergy Appl. Immunol. 34: 18-31.

29. Dickler, H. B. 1976. Lymphocyte receptors for immunoglobulin. Adv. Immunol. 24: 167-214.

30. Moretta, L., M. Ferrarini, M. C. Mingari, A. Moretta, and S. R. Webb. 1976. Subpopulations of human T-cells identified by receptors for immunoglobulin and mitogen responsiveness. J. Immunol. 117: 2171-2174.

31. Moretta, L., M. Ferrarini, M. L. Durante, and M. C. Mingari. 1975. Expression of a receptor for IgM by human T-cells in vitro. Eur. J. Immunol. 5: 565-569.

32. Moretta, L., S. R. Webb, C. E. Grossi, P. M. Lydyard, and M. D. Cooper. 1977. Functional analysis of two human Tcell populations: help and suppression of B-cell responses by T-cells bearing receptors for IgM or IgG. J. Exp. Med. 146: $184-200$.

33. Winfield, J. B., P. I. Lobo, and M. E. Hamilton. 1977. Fc receptor heterogeneity: immunofluorescent studies of $B$, $\mathrm{T}$, and "third populations: lymphocytes in human blood with rabbit IgG b4/anti-b4 complexes. J. Immunol. 119: 1778-1784.

34. DeHoratius, R. J., D. Santoli, and T. Pincus. 1978. Decreased levels of $T$ gamma cells in active systemic lupus erythematosus (SLE). Arthritis Rheum. 21: 553. (Abstr.)

35. Alarcon-Segovia, D., and A. Ruiz-Argüelles. 1978. Decreased circulating thymus-derived cells with receptors for the Fc portion of immunoglobulin $G$ in systemic lupus erythematosus. J. Clin. Invest. 62: 1390-1394.

36. Hofman, F., A. Cohen, D. Zipori, R. Burstein, Z. Benich, and J. Haimovich. 1977. Binding of $F(a b)_{2}{ }^{\prime}$ of normal human IgG to human lymphocytes. J. Immunol. 119: 2209-2211.

37. Lerner, R. A., C. B. Wilson, B. C. Del Villano, P. J. McConahey, and F. J. Dixon. 1976. Endogenous oncornaviral gene expression in adult and fetal mice: quantitative, histologic, and physiologic studies of the major viral glycoprotein, gp 70. J. Exp. Med. 143: 151-166.

38. Yoshiki, T., R. C. Mellors, M. Strand, and J. T. August. 1974. The viral envelope glycoprotein of murine leukemia virus and the pathogenesis of immune complex glomerulonephritis of New Zealand mice. J. Exp. Med. 140: 10111027

39. Datta, S. K., N. Manny, C. Andrzejewski, J. AndreSchwartz, and R. S. Schwartz. 1978. Genetic studies on autoimmunity and retrovirus expression in crosses of New Zealand black mice. I. Xenotropic virus. J. Exp. Med. 147: 854-871.

40. Datta, S. K., P. J. McConahey, N. Manny, A. N. Theofilopoulos, F. J. Dixon, R. S. Schwartz. 1978. Genetic studies of autoimmunity and retrovirus expression in crosses of New Zealand black mice. II. The viral envelope glycoprotein. gp 70. J. Exp. Med. 147: 872-881.

41. Curd, J. G., J. S. Sundsmo, W. P. Kolb, H. G. Bluestein, and H. J. Muller-Eberhard. 1978. Neoantigen of the membrane attack complex of human complement. Occurrence on peripheral blood leukocytes from patients with systemic lupus erythematosus. Arthritis Rheum. 21: 177-182. 